\title{
John Fothergill and angina pectoris
}

\author{
William L Proudfit
}

Correspondence to:

Dr William L Proudfit, Cleveland Clinic

Foundation, One Clinic Center, 9500 Euclid Avenue Cleveland, Ohio 44195, USA

Accepted for publication 23 May 1991

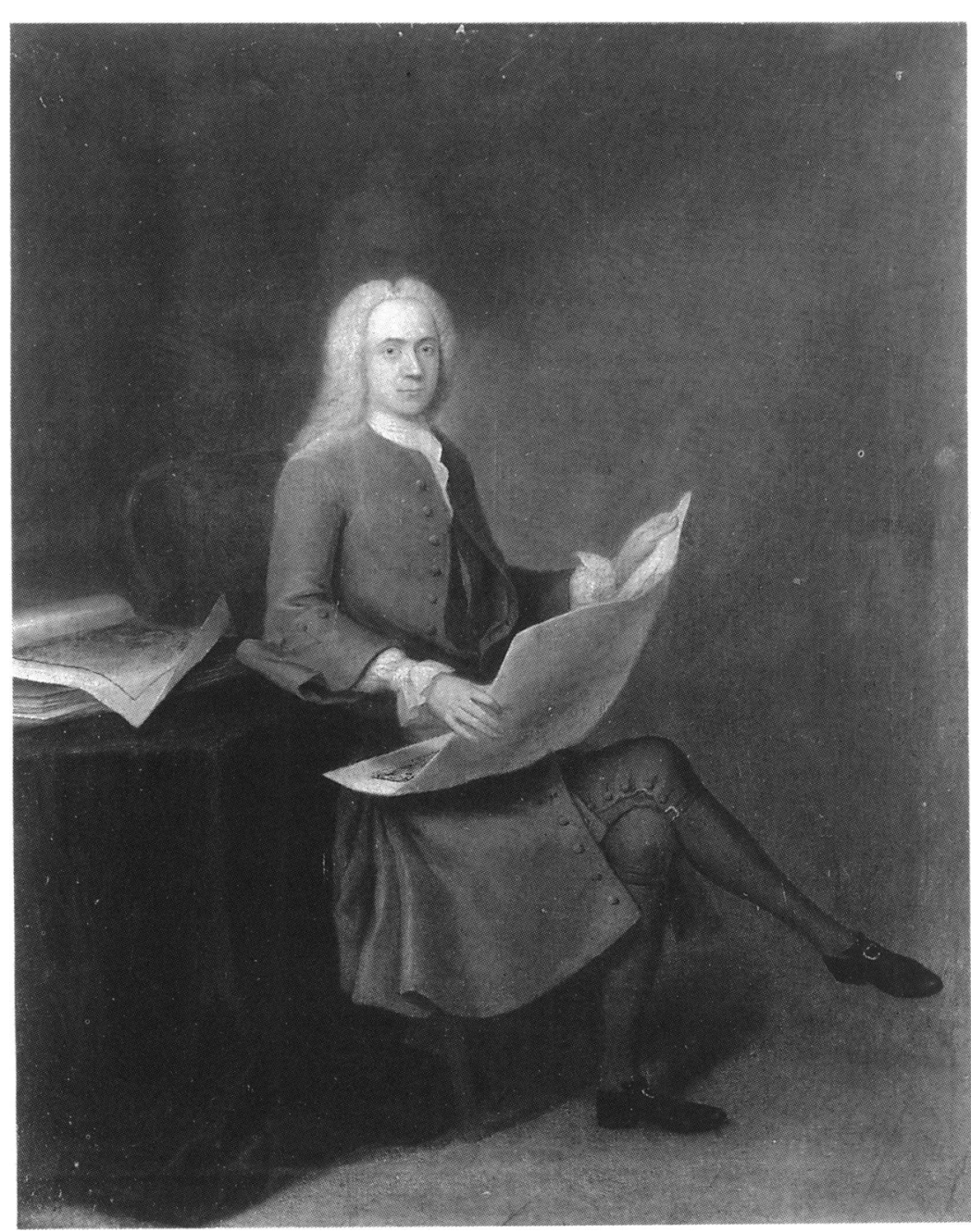

From an oil portrait of John Fothergill by an unknown artist, courtesy of the Royal College of Physicians.
William Heberden presented his original description of angina pectoris to the College of Physicians in London on 21 July $1768 .{ }^{1}$ In it he said that he "consulted an able physician of long experience, who told me that he had known several ill of it, and that all of them had died suddenly." Although the latter phrase does not fit precisely the experience of John Fothergill, it is likely that he was the physician mentioned. Fothergill was a friend of Heberden, who supported his application to the College of Physicians. ${ }^{2}$ Fothergill had recognised angina pectoris long before Heberden described and named it in his lecture. ${ }^{3}$

\section{General background}

John Fothergill was born in Yorkshire in 1712, two years after Heberden. ${ }^{45} \mathrm{He}$ was the son of a prosperous Yorkshire farmer and preacher of the Quaker faith. Fothergill received his medical degree from the University of Edinburgh in 1736. Although he went to St Thomas's Hospital, London after graduation and stayed at least two years, it is not clear what he did between 1738 and 1740 . It is probable that he made a start in private practice. He received a box of seeds packed by John Bartram, the famous self educated American Quaker naturalist, in September 1738, delivered by Dr Thomas Bond, a Philadelphia physician. ${ }^{6}$ Possibly Bond met Fothergill in St Thomas's Hospital; and Bond, the same age as Fothergill, gave the seeds as a token of esteem. Bond returned to Philadelphia from Paris in the early 1740 s and sang the praises of Fothergill to Bartram. Correspondence sprang up between Bartram and Fothergill and lasted the rest of Bartram's life. In 1740 Fothergill travelled to Belgium, Holland, and Germany with friends and started his real practice when he returned to London the same year. His practice flourished because of his professional ability and his free service to the poor, but remuneration was low initially. Gradually a larger number of affluent citizens consulted him and after his widely translated paper on sore throat (an original description of diphtheria, but some cases had scarlet fever) was published in 1748 , he was famous and busy. In addition to medical practice, he did a great deal of medical and scientific writing and was a medical editor. He was active in medical societies and was interested in medical education. Fothergill was elected Fellow of the Royal Society in 1768.

Despite the pressure of a large practice, Fothergill continued to be concerned about the plight of the poor and often the monetary component of his medical care went from doctor to patient rather than the usual direction. In addition he was active in private philanthrophy and public causes. His societal interests included vital statistics, condition of prisons, police, internal commerce, public baths, cemeteries, abolition of slavery, and a Quaker school for children. Fothergill's father had visited America for evangelistic purposes and this may have influenced John in the 
development of many friendships in the colonies. Fothergill had extensive correspondence with his American friends and supported financially schools in Willamsburg, Philadelphia, and New York. He made large contributions to the University of Pennsylvania and the Pennsylvania Hospital. $\mathrm{He}$ was one of the earliest members of the American Philosophical Society. Fothergill was an active apologist for the American colonists and he and Benjamin Franklin, his friend and patient, carried out intense negotiations in an effort to prevent rupture of diplomatic relations. Fothergill remained supportive of Americans until his death in $\mathbf{1 7 8 0 .}$

Although Fothergill was famous in London and the American colonies for other reasons, he was most renowned in the mind of the British general public outside London and on the European continent as a horticulturalist. $\mathrm{He}$ was a botanist and he constructed extensive gardens and an enormous greenhouse that included the largest variety in all Europe, according to Sir Joseph Banks, the President of the Royal Society. Linnaeus named a plant Fothergilla after his friend, an appropriate designation for an American plant. Fothergill's gardens included many American plants and shrubs whose seeds, cuttings, or whole plants were sent by his friend John Bartram. ${ }^{6}$ $\mathrm{He}$ and Bartram developed original techniques for transporting these specimens to London. Fothergill also had an extensive collection of shells and smaller but select accumulations of butterflies and minerals.

John Fothergill made significant medical contributions in addition to his description of diphtheria. He wrote an excellent account of "sick head-ach" (migraine). Trigeminal neuralgia was described first by Fothergill. The second part of his first paper on angina pectoris is an accurate description of two cases of what now is called Pickwickian syndrome. It is ironic that his name is not attached to any of his original descriptions.

\section{Angina pectoris}

If Fothergill was Heberden's “able physician of long experience" why was he not mentioned by name? A large botanical volume was dedicated to Fothergill, but he withdrew his initial approval before publication because he did not think himself worthy. It may be that this attitude was responsible for Heberden's omission, for Heberden was generous in his support of colleagues. Fothergill reported postmortem examinations of two of his patients who had been diagnosed as having angina pectoris. His two reports were published consecutively in $1776 .{ }^{37} \mathrm{He}$ stated that "the disease was of that kind which is so fully and judiciously described by Dr Heberden." It is evident that Fothergill gave an oral presentation of his first case to the Society of Physicians of London, but the date is not given. The patient died 14 May 1774 and Fothergill must have made his report late in 1774 or early 1775 . He states in the second case report that death occurred on 13 March
1775 and that this date was after the first case report had been delivered.

Fothergill gave detailed case histories of the patients, both of whom died suddenly. In the first paper he mentioned the postmortem findings of another person who had experienced angina and anasarca. A "small ossification in one of the mitral valves" was found. Fothergill states that patients with angina usually had "an irregular and intermitting pulse" even when free from pain. This combination of observations led him to ask the prosectors in the first reported case "to attend to the condition of the heart with all possible accuracy." The prosectors were "the Langleys, two judicious surgeons in the neighbourhood". These appear to have been Arnold and Thomas Langley who practiced at Red Lion Square, London, at the time of compilation of the 1777 list of members of the Corporation of Surgeons, the earliest roll possessed by The Royal College of Surgeons of England (personal communication from I $F$ Lyle, librarian). They found "near the apex, a small white spot as big as a sixpence, resembling a cicatrix." The coronary arteries were not mentioned in the necropsy report. Fothergill wondered whether the excessive amount of fat in the mediastinum, pericardium, and omentum might have been responsible for this patient's angina. Accordingly he went on to describe two morbidly obese, somnolent young people. A young man lost weight on a vegetable diet and regained his health and a young woman improved with weight loss, but relapsed with abandonment of her diet and died suddenly at age 27 . At necropsy, nothing was found except for obesity. Lacking more specific treatment Fothergill advised a vegetable diet for patients who had angina.

In his first report Fothergill mentioned that he had seen a man about 30 years of age who had angina pectoris, the youngest victim he had observed. He had been consulted by the patient "above 20 years ago"-presumably before 1754, at least 14 years before Heberden's original report. This man showed gradual improvement and then disappearance of angina, the only case of complete "cure" of the condition in Fothergill's experience. $\mathrm{He}$ had observed others whose angina had lessened "but for the most part .... the prognostic is unfavourable."

In the second case, John Hunter, "that very skilful and accurate anatomist", was engaged to do the postmortem examination, which showed mitral and aortic valvular disease but apparently not very severe in extent. Calcifications were noted in the aorta. "The two coronary arteries, from their origin to many of their ramifications upon the heart, were become one piece of bone." Scars were found in the left ventricle. Despite the fact that Hunter had encountered coronary disease at necropsy in 1770, he apparently did not examine the coronary arteries of Heberden's case in May $1772 .^{89}$ Hunter himself had angina by 1773 , so it is remarkable that his postmortem findings of Fothergill's patient in 1775 did not seem to impress him. ${ }^{10} \mathrm{He}$ said 
that "there was nothing very remarkable in his case worth taking notice of." in giving the case history, wrote that "in a sudden and violent transport of anger, he fell down and expired immediately." The same fate in the same circumstances awaited John Hunter in 1793, and Hunter had anticipated its possible occurrence. ${ }^{10}$

In his discussion of this case, Fothergill said that "the state of the parts about the heart fully shew, that under such circumstances, it is impossible to bear with impunity the effects of sudden and violent agitations, whether they arise from gusts of passion, or suddenly accelerated muscular motion." $\mathrm{He}$ did not specify which of the cardiac abnormalities might be responsible for angina pectoris nor did he speculate on the possible mechanism.

\section{Evaluation}

It has been said that Fothergill was the first to ascribe angina pectoris to coronary artery disease. A more accurate statement is that he was one of the first to suspect the association of cardiac disease and angina pectoris. The date of Fothergill's original suspicion cannot be determined, but John Wall, in a letter to Heberden dated 30 May 1772, attributed angina pectoris to aortic stenosis demonstrated at necropsy. Heberden read Wall's report to the College of Physicians on 17 November 1772, although publication was delayed until $1785 .{ }^{11}$ Certainly Fothergill did not emphasise the importance of coronary disease. It remained for Edward Jenner and Samuel Black independently to lay the foundation for the ischaemic theory of causation of angina. ${ }^{12}$

Fothergill died in December 1780 of prostatic obstruction probably due to carcinoma. Benjamin Franklin wrote to a physician friend, "I think that a worthier man never lived." 13

1 Heberden W. Some account of a disorder of the breast. Medical Transactions, published by the College of Physicians in London 1772;2:59-67.

2 Heberden E. William Heberden: physician of the age of reason. London: Royal Society of Medicine Services, 1989.

3 Fothergill J. Case of angina pectoris, with remarks. Medical Observations and Inquiries by a Society of Physicians in London 1776;5:233-51.

4 Lettson JC. The works of John Fothergill. Volume III. London: Charles Dillog, 1783

5 MacMichael $\mathbb{W}$. Lives of British physicians. London: Murray, 1830

6 Berkeley E, Berkeley DS. The life and travels of John Bartram. Tallahassee: Florida State University Book, 1982 .

7 Fothergill J. Farther account of the angina pectoris. Medical Observations and Inquiries by a Society of Physicians in London 1776;5:252-8.

8 Hunter J. Case Books, transcribed in five volumes by William Clift, 1826. Unpublished. Library of the Royal College of Surgeons of England.

9 Parry $\mathrm{CH}$. An inquiry into the symptoms and causes of the syncope anginosa, commonly called angina pectoris. Bath: $\mathrm{R}$ Crotwell, 1799.

10 Hunter J. A treatise on blood, inflammation and gun-shot wounds to which is prefixed a short account of the author's life by his brother-in-law Everard Home. London: $\mathrm{G}$ Nichol,

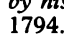

11 Wall J. A letter from Dr Wall to Dr Heberden on the same subject (angina pectoris). Medical Transactions, published by the College of Physicians in London 1785;3:12-24.

12 Proudfit WL. Origin of concept of ischaemic heart disease. Br Heart J 1983;50:209-12.

13 Garner BC, Booth CC. Chain of friendship: letters of Dr Fothergill. Cambridge: Harvard University Press, 1971. 